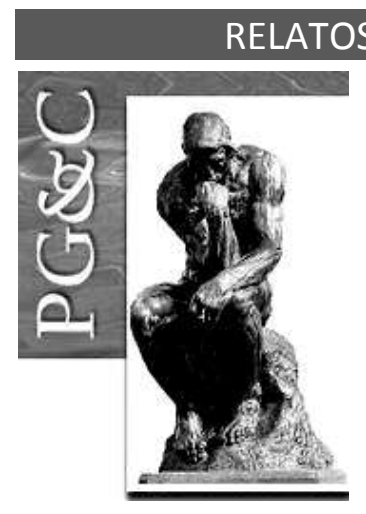

\title{
GESTÃO DO TRABALHO DOCENTE E PERCEPÇÃO DAS CONDIÇÕES DE SAÚDE DE DOCENTES DE ENSINO SUPERIOR
}

\author{
Michelle Cardoso Machado dos Santos \\ Mestre em Saúde Coletiva pela Universidade do Sul de Santa Catarina. \\ Mestre em Gestão do Conhecimento pela Universidade Cesumar, Brasil. \\ Professora da Universidade Cesumar, Brasil. \\ E-mail: micardosomsantos@gmail.com
}

Adriana Yanina Ortiz

Doutora em Educação pela Universidade de Lisboa, Portugal. Professora da Universidad Nacional de Salta, Argentina.

E-mail: ortizadrianayanina@gmail.com

Solange Franci Raimundo Yaegashi

Doutora em Educação pela Universidade Estadual de Campinas, Brasil. Professora da Universidade Estadual de Maringá, Brasil.

E-mail: solangefry@gmail.com

Arthur Gualberto Barcelar da Cruz Urpia

Doutor em Economia pela Universidade Federal do Rio de Janeiro, Brasil. Professor da Universidade Cesumar, Brasil.

E-mail: arthur.urpia@unicesumar.edu.br

Regiane da Silva Macuch

Doutora em Ciências da Educação pela Universidade do Porto, Portugal. Professora da Universidade Cesumar, Brasil.

E-mail: rmacuch@gmail.com

\section{Resumo}

A Universidade é tida como uma organização que produz conhecimento científico e que atualmente precisa organizar suas ações para a produção e gestão do conhecimento no sentido de sua própria sobrevivência e cumprimento da missão de formar novos profissionais. O docente é um personagem central neste processo, visto que suas funções estão diretamente relacionadas com a produção e disseminação do conhecimento, além do desenvolvimento de pessoas. Entretanto, a função docente também é fortemente influenciada pelas mudanças sociais e econômicas do mundo globalizado. Assim, este estudo visa compreender como a percepção da própria saúde pode afetar o processo de gestão do trabalho docente de um grupo de docentes de ensino superior. Para este fim foram aplicados questionários à 80 docentes do ensino superior de uma instituição privada, com questões sobre aspectos socioeconômicos e profissionais, além da versão curta do questionário genérico de avaliação de qualidade de vida- SF-36. Os dados obtidos indicam que a saúde influencia na gestão do trabalho pedagógico, em especial sobre produção científica e inovação de metodologias em sala de aula. Desta forma, conclui-se que os processos de gestão do conhecimento podem auxiliar na melhoria das condições de saúde docente e, consequentemente, na gestão do seu trabalho.

Palavras-chave: Docentes. Ensino superior. Gestão do conhecimento. Qualidade de vida. Gestão do trabalho. 
Michelle Cardoso Machado dos Santos; Adriana Yanina Ortiz; Solange Franci Raimundo Yaegashi;

Arthur Gualberto Barcelar da Cruz Urpia; Regiane da Silva Macuch

\title{
TEACHING WORK MANAGEMENT AND PERCEPTION OF HEALTH CONDITIONS OF HIGHER EDUCATION TEACHERS
}

\begin{abstract}
The University is considered an organization that produces knowledge and currently needs to organize its actions for production and management of knowledge about its own survival and fulfillment of the mission to train new professionals. The teacher is a central character in this process, since his work is directly related to the production and dissemination of knowledge, as well as the development of people. However, the teaching function is also strongly influenced by the social and economic changes of the globalized world. Thus, this research aims to understand how the perception of one's own health can affect the management process of the teaching work of a group of higher education teachers. For this purpose, questionnaires were applied to 80 teachers of higher education of a private institution, with questions about socioeconomic and professional aspects of this teacher, in addition to the short version of the Medical Outcomes Short-Form Health Survey SF-36. The data obtained indicate that health influences the management of pedagogical work, especially in the scientific production and innovation of methodologies in the classroom. In this way, it can be concluded that knowledge management processes can help improve the health conditions of these teachers and, consequently, the management of teaching work.
\end{abstract}

Keywords: Teachers. Higher education. Knowledge management. Quality of life. Work management.

\section{INTRODUÇÃO}

O Século XXI está marcado como a Era do Conhecimento. A Sociedade do Conhecimento da atualidade é fruto de profundas mudanças sociais, culturais e econômicas advindas da Terceira Revolução Industrial, que uniu o conhecimento científico e produção industrial. $O$ desenvolvimento de novas tecnologias promotoras de comunicação permeou o processo de globalização e de acesso rápido à informação. Neste ambiente, a relação entre conhecimento e produção de riqueza tornou-se íntima e indispensável. O conhecimento passou a ser valorizado como capital fundamental para a sobrevivência das organizações, visto que é imprescindível para o desenvolvimento de novos processos, tecnologias e inovações. Desse modo, em uma era onde a alta tecnologia está presente nos mais diversos meios, o que "se conhece" passou a ser um diferencial entre pessoas e empresas (MARTINS; FERREIRA, 2015; CHERMAN; ROCHA-PINTO, 2016).

Sob esta ótica, o desenvolvimento de competências para o desenvolvimento, aplicação e gestão do conhecimento tornou-se primordial para a sobrevivência no mercado de trabalho atual, incluindo a docência. $O$ ensino superior constitui-se um contexto propício para o desenvolvimento destas competências: por meio do estudo de uma determinada área do conhecimento, o indivíduo adquire habilidades e competências para a atuação no ambiente de trabalho (PERRENOUD, 2000). Le Boterf (2005), enfatiza que competências se referem sempre a pessoas e que toda competência é individual, porém, também coletiva. Para ser competente em algo, há a necessidade de organização das informações e raciocínio sobre as situações, não apenas de saber fazer e saber ser.

No processo de construção de novos conhecimentos, habilidades e competências, há a presença daquele indivíduo dedicado ao ensino e ao desenvolvimento de pessoas - o professor. A função do professor ou docente sofreu com as mudanças da Revolução Industrial e do desenvolvimento de novas tecnologias. Aquele que antes era o total detentor do conhecimento teve que adaptar-se a alunos que possuem a informação "na palma de suas mãos". Ademais, há que lembrar-se que a atividade docente se vincula ao processo intelectual, investigativo e criativo, o que se contrapõe ao método mercadológico imposto nas últimas

Perspectivas em Gestão \& Conhecimento, João Pessoa, v. 10, n. 2, p. 143-158, maio/ago. 2020. 
décadas. A atuação docente na atualidade está relacionada com demandas imediatas, atualizações constantes e alta produtividade, o que afeta o ritmo no contexto do trabalho e tem afetado diretamente as condições de saúde dos professores (LEITE, NOGUEIRA, 2017; BERNARDO, 2014). Esta alta gama de atividades tem resultado no adoecimento do professor (ANDRADE; CARDOSO, 2012). A mídia, assim como estudos científicos atuais na área (CAMPOS; CUNHA, 2017; BERNARDO, 2014; LEITE; NOGUEIRA, 2017), alertam para o uso cada vez mais comum de medicamentos para ansiedade, depressão e doenças de ordem física em todas as faixas etárias. Tais pesquisas realizadas com a população de professores mostram altos índices de absenteísmo e afastamento no trabalho decorrente de problemas de saúde.

O tema saúde ocupacional tem sido discutido dentro dos mais diferentes campos profissionais e no que tange à saúde do docente, estudos descrevem alta gama de disfunções diretamente relacionadas à atuação deste profissional. Desta forma, cuidar da saúde dos profissionais da educação passou a ser um investimento na produtividade das organizações que ofertam serviços de educação, assim como demais organizações (ILO, 2012).

O professor é um profissional cujo ofício requer um alto grau de dedicação intelectual e afetiva, somadas às muitas atividades burocráticas que exigem horas de trabalho além do expediente. Assim sendo, este estudo tem por objetivo proporcionar melhor entendimento sobre a situação atual da função docente e sua relação com a saúde deste profissional a fim de refletir sobre meios para intervenções assertivas para melhorias com base nas estratégias e ferramentas da gestão do conhecimento.

\section{DESENVOLVIMENTO}

A Revolução Industrial e o desenvolvimento de novas tecnologias modificaram a sociedade de tal modo que o papel do ensino precisou ser reavaliado e redirecionado para atender às necessidades deste novo período. Em uma sociedade que possui fácil acesso à inúmera necessitam adaptar-se a estudantes multiculturais, complexos e intensos (LEITE; NOGUEIRA, 2017).

Neste contexto, a necessidade de gerir o conhecimento surge da dificuldade em lidar com as complexas mudanças do final do século XX. Para garantir a competitividade no mercado, as organizações precisam dispor de técnicas e estratégias para analisar, organizar, aprimorar, manter e compartilhar o conhecimento individual e coletivo (DALKIR, 2013). A gestão do Conhecimento (GC) constitui um campo de atuação multidisciplinar, aplicada às mais diversas áreas do mercado. Esta obteve grande difusão com o trabalho de Nonaka e Takeuchi em meados da década de 90, quando estes autores descreveram que o conhecimento adquirido por meio das experiências humanas (tácito) poderia ser convertido em um conhecimento descrito, registrado e capaz de ser transferido (explícito) (NONAKA; TAKEUCHI, 1993).

Independente do modelo adotado para criação e disseminação do conhecimento organizacional, não há como negar o imenso valor que o conhecimento possui para as organizações atuais. Grandes exemplos de sucesso são baseados em modelos de GC de forma constante e organizada. Gerir o conhecimento consiste em verificar os conhecimentos que serão úteis à determinada organização, garantindo vantagem competitiva no mercado (AGUIAR, 2016).

As Instituições de ensino superior (IES) constituem organizações responsáveis pelo ensino superior e, como qualquer instituição de ensino, possuem grande responsabilidade, pois, segundo Delors (2003), "aquilo que fazemos hoje será determinante para o tipo de sociedade que desejamos ver instaurar-se tanto no que se refere aos seus valores quanto ao bem-estar material e cultural de seus cidadãos. Entretanto, da mesma forma que as complexas

Perspectivas em Gestão \& Conhecimento, João Pessoa, v. 10, n. 2, p. 143-158, maio/ago. 2020. 
mudanças do final do século XX diante do surgimento das novas tecnologias, da globalização e crescimento das necessidades dos clientes afetaram as relações de mercado, estas também afetaram o ensino superior.

Atualmente, as IES precisam formar profissionais habilitados a atuarem em um mundo cada vez mais tecnológico, de mudanças constantes e rápidas e nas mais diversas áreas do conhecimento. Segundo Altbach (2009), o objetivo principal das organizações que atuam no ensino superior passou a ser "fornecer habilidades técnicas necessárias para um número cada vez maior de empregos e profissões que requerem conhecimentos sofisticados e uma educação que estimule a habilidade de pensar criticamente". Estes mesmos autores salientam que o que diferencia uma IES de outras organizações é que ela é "formada por pessoas e para pessoas", portanto, revestida de comportamentos, sentimentos, falhas, altos e baixos, emoções, saúde e doença física e mental, comuns a todos os humanos. Nesse sentido, a atual pandemia representada pela Covid-19 trouxe um novo estresse, as pessoas precisaram continuar se encontrando nas IES sem estarem fisicamente presentes. Houve assim, nova pressão focada no desenvolvimento de habilidades tecnológicas para dar conta desse "novo normal". Isto implicando em uma gestão intensiva do conhecimento com foco nas pessoas.

Dentre os personagens envolvidos no ensino superior, merece destaque o professor/docente. Para Pimenta e Anastasiou (2002), o docente é o gestor do processo de ensino-aprendizagem. A ele cabe a função de facilitar, mediar, induzir, motivar e fomentar o conhecimento. Entretanto, Borges e Cecílio (2018) descrevem que, apesar do objetivo fim ao qual a função docente se destina se manter o mesmo, a forma como atua no processo de construção do conhecimento passou por profundas mudanças a partir de meados do século XX. Segundo os referidos autores, a atividade docente está cada vez mais desafiante, em especial no que tange a gestão das aulas, dos conteúdos, das estratégias de ensino e do processo de avaliação. Yaegashi, Benevides-Pereira e Alves (2013) enfatizam que os rápidos avanços tecnológicos, científicos e as mudanças sociais perpassam os muros escolares, colocando novos desafios à educação, exigindo novas competências, capacidade para resolver situações não previstas, até mesmo desconhecidas e uma renovação dos princípios e métodos de trabalho nas escolas. Novametne a atual pandemia reforçou a necessidade de professores e alunos aprenderem, em pouquíssimo tempo, aprender a usar Novas Tecnologoas Digitais de Comunicação - TDIC.

Diante desta realidade, Perrenoud em meados dos anos 2000, apresentou novas competências para se ensinar no século XXI. Segundo o autor (2000), para ensinar no século $\mathrm{XXI}$, o professor precisa desenvolver competências para atuar na organização em relação às situações de aprendizagem, na administração da progressão destas aprendizagens, na capacidade de envolver o discente em sua própria aprendizagem, no trabalho em equipe, no uso das novas tecnologias, na participação nas atividades administrativas e no gerenciamento de sua própria formação contínua.

Atualmente, o conhecimento e a capacidade de inovação constituem parâmetros e estratégias de competitividade e perpetuação de existência no mundo atual e, sendo o ensino superior altamente vinculado aos interesses industriais e econômicos, este representa uma importante ferramenta de desenvolvimento econômico e social de um país (BORGES; CECíLIO, 2018). Bolfer (2008) considera que o professor deve ter "objetivos claros de sua função", não sendo mais possível associar à docência apenas como uma vocação e uma missão. Segundo a autora (2008), para ser professor não "basta gostar de ensinar e dominar conhecimentos específicos de determinada área e algumas habilidades técnicas".

À paixão pela docência, faz-se necessário associar a articulação dos conhecimentos a fim de colocá-los em ação, promovendo a emancipação dos alunos enquanto cidadãos. Nesta missão, é importante o docente ter a consciência da necessidade de aprimorar suas competências, pois com este "novo papel dos professores, com a evolução da formação

Perspectivas em Gestão \& Conhecimento, João Pessoa, v. 10, n. 2, p. 143-158, maio/ago. 2020. 
contínua, com as reformas da formação inicial e com as ambições das políticas educativas" (PERRENOUD, 2000), altera-se, assim, o papel do docente, o que exige maiores ações bem como a gestão deste papel, que pode gerar neste, adoecimentos.

Com relação à saúde docente, muitos autores debruçaram-se sobre este tema para entender as condições de saúde docente (VALE et al., 2015; LIU et al., 2015; DALAGASPERINA; MONTEIRO, 2016). Os altos índices de absenteísmo do trabalho e aposentadorias precoces entre professores tem levado pesquisadores das mais diferentes áreas a buscar os motivos da falta de saúde docente, sendo possível observar que a maioria dos autores considera o fator "estresse ocupacional" como o principal responsável pela baixa saúde desse profissional (SANTOS et al., 2016; LIU et al., 2015).

Estresse ocupacional é um conceito relacionado a um complexo componente físico e psíquico proveniente de exigências do ambiente de trabalho e constitui uma relevante questão de saúde mundial, visto que traz impactos negativos tanto na saúde do trabalhador como na produtividade das organizações (ILO, 2012). Entretanto, há que se considerar que o nível de estresse ocupacional está relacionado principalmente a forma com a qual o trabalhador faz a gestão do que lhe é imposto pelo trabalho, a partir de suas capacidades, habilidades e expectativas profissionais. A forma como o indivíduo percebe o ambiente de trabalho e as funções por ele exercidas influenciam diretamente o seu desempenho. No caso do professor, esta percepção influenciará no seu relacionamento com os colegas, com a profissão e no próprio processo de ensino-aprendizagem (COLLIE et al., 2012). Ademais, Souza et al. (2017) ressaltam que o trabalho docente na atualidade está relacionado com demandas variadas e imediatas, o que tem aumentado o tempo que o docente despende com o trabalho.

Bolfer (2008) destaca a atividade docente como uma atividade pensante, ativa e interativa, que atribui ao professor as atividades de "perceber o todo, perceber as relações com o todo inserindo a emoção e o afeto, estar disponível, estar aberto, tratar bem os alunos, conversar, explicar, influir no conhecimento das pessoas, ter atitude firme, saber retomar, estimular, mostrar o caminho, ser companheiro do aluno e ser agente de transformação".

Andrade e Cardoso (2015) afirmam que na literatura há diversas fontes relacionando atividades profissionais que envolvem intensas relações interpessoais e altos níveis de estresse. Estas autoras alegam que "os docentes formam uma categoria especialmente exposta aos riscos psicossociais", tendo em vista as diversas funções exercidas por este profissional e o intenso envolvimento emocional que estas funções exigem.

Nas últimas décadas, diversos estudos versam acerca da saúde docente e relacionam disfunções físicas e mentais. Dentre as alterações físicas, as mais recorrentes são dores musculoesqueléticas, distúrbios das cordas vocais e hipertensão arterial (MORENO et al., 2016). Já no que tange à saúde mental, há maior referência sobre a depressão, ansiedade, estresse, distúrbios do sono e Síndrome de Burnout (VALE et al., 2015; SOUZA et al., 2017; LIU et al., 2015; DALAGASPERINA; MONTEIRO, 2016; YAEGASHI, BENVIDES-PEREIRA; ALVES, 2013).

Incluída recentemente pela Organização Mundial de Saúde como uma doença exclusivamente ocupacional, a Síndrome de Burnout é definida como uma síndrome conceituada como resultante do estresse crônico no local de trabalho que não foi gerenciado com sucesso. É caracterizada por três dimensões: sentimentos de exaustão ou esgotamento de energia; aumento do distanciamento mental do próprio trabalho, ou sentimentos de negativismo ou cinismo relacionados ao próprio trabalho; e redução da eficácia profissional (WORLD HEALTH ORGANIZATION, 2019).

Segundo Andrade e Cardoso (2015, p.133), "a expressão inglesa Burnout designa aquilo que deixou de funcionar por exaustão de energia, esgotamento físico, psíquico e emocional, em decorrência da má adaptação do indivíduo a um trabalho altamente estressante e com grande carga tensional". Vale et al (2015) relacionam a presença desta síndrome em docentes às expressivas mudanças no cenário educacional das últimas décadas,

Perspectivas em Gestão \& Conhecimento, João Pessoa, v. 10, n. 2, p. 143-158, maio/ago. 2020. 
tanto em termos "sociais, tecnológicos e pedagógicos", o que gera um aumento na "quantidade e intensidade de estressores ocupacional".

Certamente que o sentimento de bem-estar influencia diretamente na produtividade do indivíduo, assim como na qualidade da sua produção, sendo perfeitamente aplicável ao ambiente escolar, visto que um professor também produz mais e melhor quando se sente bem no ambiente de trabalho (ABREU et al., 2016), como demonstrado no estudo de Barbosa et al., (2018) com professores do ensino superior privado.

\section{MATERIAIS E MÉTODOS}

A fim de responder às perguntas deste estudo, desenvolveu-se uma pesquisa de abordagem quantitativa, do tipo exploratório, descritivo e transversal. A pesquisa foi realizada em uma instituição de ensino superior (IES) privada brasileira no período de fevereiro a maio de 2019.

Os sujeitos da pesquisa foram 80 docentes do ensino presencial da referida IES que aceitaram participar da pesquisa por meio da assinatura do termo de consentimento livre e esclarecido (TCLE) para uso dos dados obtidos na divulgação em periódicos científicos. Docentes que ministravam aulas no ensino à distância foram excluídos da amostra. A coleta dos dados foi realizada após apreciação e aprovação pelo Comitê de Ética em Pesquisa Envolvendo Seres Humanos. ${ }^{1}$

A coleta de dados consistiu na aplicação de dois questionários estruturados. 0 primeiro foi construído pelos pesquisadores com objetivo de conhecer os aspectos sócios econômicos e profissionais dos docentes envolvidos e avaliou, dentre outros aspectos, o tempo de atuação na docência, número de cursos em que ministra aulas, carga horária semanal em sala de aula e a percepção da influência da atividade docente sobre sua saúde.

O segundo questionário verificou a percepção do indivíduo no que tange sua qualidade de vida relacionada às suas condições de saúde. Conhecido como Short Form Health Survey (SF-36), é um instrumento validado no Brasil por Ciconelli (1999) e amplamente utilizado para avaliar as condições de saúde de uma população. O SF-36 constitui-se em 36 itens que avaliam a percepção do indivíduo em relação à sua saúde por meio de oito domínios: Capacidade funcional, Limitação por aspectos físicos, Dor, Estado geral de saúde, Vitalidade, Aspectos sociais, Aspectos emocionais e Saúde mental. As respostas são categorizadas de acordo com uma raw scale, de 0 a 100, onde 0 representa uma qualidade de vida pior e 100 uma melhor qualidade de vida de acordo com a percepção de saúde individual dos respondentes.

Os questionários foram aplicados por meio da ferramenta Google Forms ${ }^{\circledR}$, compartilhada por e-mail. Esta ferramenta gratuita possibilita que questionários possam ser compartilhados e respondidos via web. Os participantes acessaram o link enviado no e-mail, assinalaram a anuência ao TCLE e responderam às questões por meio de computadores, tablet ou celulares. Os questionários foram disponibilizados a 260 professores do ensino presencial da referida instituição, totalizando $50 \%$ do total de docentes, conforme dados obtidos no departamento de Recursos Humanos da IES.

A forma de envio principal do questionário foi por e-mail, no qual constava um pequeno texto introdutório sobre a pesquisa com o convite à participação voluntária dos indivíduos a partir do link de acesso ao questionário. O mesmo texto e o link foram enviados aos coordenadores dos cursos de graduação presencial da IES, solicitando a estes o encaminhamento de tal mensagem aos seus grupos de professores. Novas mensagens foram

\footnotetext{
${ }^{1}$ Centro Universitário de Maringá - UNICESUMAR, órgão vinculado ao Conselho Nacional de Ética em Pesquisa CONEP sob o número 3.228.071 e CAAE número 09897519.6.0000.5539.
}

Perspectivas em Gestão \& Conhecimento, João Pessoa, v. 10, n. 2, p. 143-158, maio/ago. 2020. 
enviadas após 20 e 30 dias para reforçar o convite. O questionário ficou disponível para resposta durante o período de 60 dias.

Os dados obtidos foram inicialmente tabulados em uma planilha do programa Microsoft Excel ${ }^{\circledR}$, sendo estes categorizados em variáveis numéricas e de acordo com os níveis de medida e com sua função estatística. Após a devida tabulação, os dados foram exportados para o programa estatístico IBM-SPSS ${ }^{\circledR}$, no qual foram analisados inicialmente de forma descritiva e, posteriormente, com análise de relação entre as variáveis, de acordo com os objetivos da pesquisa.

\section{RESULTADOS E DISCUSSÃO}

Os 80 questionários foram respondidos na íntegra e a Tabela 1 apresenta a caracterização da amostra segundo dados classificados pelos autores como "dados profissionais". O interesse em pesquisar dados profissionais como tempo de atuação na docência, número de cursos onde ministra aulas e horas por semana dedicados às funções docentes surgiu da revisão de literatura. Esta apresenta relações entre os mencionados itens com a forma de gestão destas diferentes funções de acordo com o tempo de atuação na docência, assim como da repercussão da profissão na saúde física e emocional destes indivíduos.

Tabela 1 - Caracterização da amostra segundo dados profissionais

\begin{tabular}{|ccc}
\hline Tempo de atuação na docência (em anos) & Frequência & $\%$ \\
\hline 2 e 3 & 7 & 8,8 \\
\hline e 8 & 23 & 28,7 \\
\hline 8 e 20 & 9 & 11,3 \\
\hline 20 e 25 & 13 & 16,3 \\
\hline 25 e 30 & 21 & 26,3 \\
\hline Acima de 30 & 7 & 8,8 \\
\hline Número máximo de Cursos onde ministra aulas & 55 & 68,8 \\
\hline 2 & 11 & 13,8 \\
\hline 3 & 6 & 7,5 \\
\hline 4 & 8 & 10,0 \\
\hline 5 & & 55,0 \\
\hline Horas semanais em sala de aula & 44 & 30,0 \\
\hline 16 a 20 & 24 & 15,0 \\
\hline 21 a 25 & 12 & 3,8 \\
\hline Maior que 26 horas & & 17,5 \\
\hline Atividades pedagógicas fora da sala de aula (horas) & 3 & 16,3 \\
\hline Menor que 4 & 14 & 62,5 \\
\hline Entre 4 e 8 & 13 & 50 \\
\hline Entre 8 e 12 & & \\
\hline Acima de 12 & & \\
\hline
\end{tabular}

Fonte: Dados de Pesquisa (2019)

Huberman (2000), em seu texto sobre o ciclo de vida dos professores, explicita que, de acordo com o tempo em que exerce a função, o docente apresenta certas características na forma como administra os desafios do dia a dia. Dentre os respondentes deste estudo, $62,7 \%$ atuam na docência há mais de 8 anos, tendo passado pela fase denominada pelo autor de fase de "estabilização", caracterizada pelo momento em que o indivíduo "passa a ser" professor. Ou seja, a partir deste tempo de atuação na docência, estes profissionais efetivamente criam a identidade de docente, o que influencia no seu desempenho profissional. Segundo este

Perspectivas em Gestão \& Conhecimento, João Pessoa, v. 10, n. 2, p. 143-158, maio/ago. 2020. 
mesmo autor, após 10 anos de atuação na docência, o indivíduo passa para a fase de "diversificação", na qual experimenta outras experiências pessoais, com mudanças do material didático, dos modos de avaliação, da gestão da sala de aula e as sequências de conteúdo. Nesta fase, o professor já possui experiência e segurança, empenhando-se mais em equipes e comissões de apoio pedagógico, buscando ser mais ativo nos processos de gestão. Neste estudo, $11,3 \%$ estão entre 8 a 20 anos.

Próximo a completar 20 anos na carreira, onde estão 16,3\% da amostra desta pesquisa, o docente questiona-se sobre suas funções, seu papel social, sua vontade de continuar a trilhar o mesmo caminho. Esta fase é seguida da fase de serenidade e distanciamento, em que, em cerca de 25 anos em atividade, o professor supera alguns questionamentos e modifica sua perspectiva e apresenta-se menos emotivo e mais "mecânico". Em contrapartida, segundo Huberman (2000), neste momento o docente possui a serenidade de alguém com a segurança de prever situações em sala de aula, contorná-las e solucioná-las sem maiores desgastes. Acredita-se que estas fases ou experiências descritas pelo referido autor podem interferir, além da forma como o docente realiza a gestão do trabalho pedagógico, também na sua saúde.

Outro fator que pode influenciar na saúde e na gestão do trabalho docente é a quantidade de turmas nas quais este professor ministra aulas, assim como a quantidade de cursos. Santos et al. (2016), ao descreverem os efeitos da intensificação do trabalho no ensino superior em Portugal, destacam o aumento no número de alunos e turmas como um fator deletério do desempenho docente. Este mesmo fator é considerado preocupante por Cortez et al. (2017), após realizar uma revisão de literatura acerca da saúde docente no trabalho.

Segundo os dados obtidos na presente pesquisa, quase $70 \%$ da amostra ministra aulas em até 2 cursos, o que pode favorecer a semelhança entre conteúdos e disciplinas. Entretanto, $10 \%$ dos docentes relatam ministrar aulas em 5 cursos diferentes, o que o obriga a gerir diferentes perfis de alunos, além de corresponder a diferentes gestores.

Outro dado que chama a atenção e apresenta embasamento teórico na literatura é a quantidade de horas despendida por estes docentes dentro e fora da sala de aula. Apesar da maioria dos respondentes (55\%) alegarem permanecer de 16 a 20 horas em sala de aula a cada semana, uma proporção maior $(62,5 \%)$ relata manter-se envolvidos em atividades pedagógicas por mais de 12 horas por semana para além da sala de aula.

Diante dos dados presentes na literatura sobre as diversas funções que o docente da atualidade desempenha, foi questionado aos professores se eles acreditavam que o exercício da docência poderia influenciar na sua saúde. Como resposta, obteve-se uma afirmativa de 95\% dos docentes respondentes, conforme mostra a Tabela 2.

Tabela 2- Distribuição da amostra segundo a percepção de quanto o exercício da docência influencia na saúde do profissional

\begin{tabular}{lcc} 
& \multicolumn{3}{c}{ Frequência } & $\%$ \\
Sim & 76 & 95,0 \\
Não & 4 & 5,0 \\
Total & 80 & 100,0 \\
\hline
\end{tabular}

Fonte: Dados de Pesquisa (2019)

Souza et al. (2017) buscaram entender esta percepção em uma revisão de literatura sobre a atuação docente na Universidade Pública e suas condições de saúde, concluindo que a função docente afeta a saúde deste profissional, em especial devido à sobrecarga de trabalho docente. Leite e Nogueira (2017) corroboram esta percepção em outra revisão de literatura, porém, com docentes do ensino superior da área das ciências da saúde, estudos estes

Perspectivas em Gestão \& Conhecimento, João Pessoa, v. 10, n. 2, p. 143-158, maio/ago. 2020. 
realizados em sua maioria em IES públicas. No mesmo ano, Cortez et al. (2017) relataram distúrbios físicos e psíquicos relacionados à função docente.

Dalagasperina e Monteiro (2016), em pesquisa qualitativa com docentes de ensino superior, concluíram que o trabalho docente afeta tanto a saúde física quanto psíquica. Abreu et al. (2016) relatam em seus resultados que $78 \%$ dos indivíduos por eles pesquisados alegam que o exercício da docência afeta sua saúde. Liu et al. (2015) relataram que $42 \%$ dos 965 professores de ensino superior por eles pesquisados apresentavam doenças crônicas. Dados semelhantes foram encontrados em outros estudos (BARBOSA et al., 2018; SANTOS et al., 2016; PRADO, 2016; ANDRADE; CARDOSO, 2015; VALE et al., 2015), o que confirma que a percepção dos docentes pesquisados está correta: a função docente influencia sim na saúde destes profissionais.

Entretanto, fica claro que esta condição não é exclusividade dos docentes. Há anos os efeitos da saúde nas atividades de trabalhadores vêm sendo estudadas e a conclusão parece ser sempre a mesma: saúde e trabalho estão diretamente relacionados, visto que a saúde influencia no trabalho, assim como o trabalho influencia na saúde (ILO, 2012). Pospichil (2018) enfatiza a importância do cuidado com as pessoas, visto que nestas está o principal capital das organizações - o capital intelectual - considerado o principal recurso para inovação e manutenção no mundo globalizado.

Collie et al. (2012) afirmam que a saúde docente influencia seu relacionamento com colegas e alunos, com a profissão e, consequentemente, na gestão das atividades pedagógicas. Leite e Nogueira (2017) constatam que as exigências da atuação docente atual têm afetado diretamente o ritmo do contexto do trabalho e as condições de saúde dos professores.

A avaliação da própria condição de saúde está diretamente relacionada com a percepção da qualidade de vida. Esta, por sua vez, foi investigada nesta população pelo questionário SF-36, que avalia a percepção da condição de saúde relacionada à qualidade de vida por meio de oito domínios: capacidade funcional, limitação por aspectos físicos, dor, estado geral de saúde, vitalidade, aspectos sociais, limitação por aspectos emocionais e saúde mental. Os resultados obtidos após a análise descritiva dos dados estão representados na Tabela 3 e são discutidos na sequência.

Tabela 3. Percepção da qualidade de vida (\%)

\begin{tabular}{lcccccc}
\hline & Excelente & $\begin{array}{c}\text { Muito } \\
\text { Boa }\end{array}$ & Boa & Ruim & $\begin{array}{c}\text { Muito } \\
\text { Ruim }\end{array}$ & Total \\
\hline Capacidade Funcional & - & - & - & 85,0 & 15,0 & 100 \\
Limitação por aspectos físicos & 100 & 0 & - & - & - & 100 \\
Em relação a dor & - & - & - & - & 100 & 100 \\
Estado geral de Saúde & - & - & 100 & - & - & 100 \\
Vitalidade & - & 8,8 & 1,3 & 37,5 & 52,5 & 100 \\
Aspectos sociais & - & - & - & 67,5 & 32,5 & 100 \\
Limitação por aspectos emocionais & 100 & - & - & - & - & 100 \\
Saúde Mental & - & 17,5 & 17,5 & 22,5 & 42,5 & 100 \\
\hline
\end{tabular}

Fonte: Dados de Pesquisa (2019)

Os indicadores com melhores índices de avaliação pelos docentes foram: limitação por aspectos físicos, limitação por aspectos emocionais e o estado geral de saúde. Na sequência, aparecem demais dados relacionados à saúde avaliados com índices menores, como capacidade funcional, dor, vitalidade, aspectos sociais e saúde mental. Ao que parece, a população estudada possui dificuldades em alguns aspectos de saúde que influenciam em sua qualidade de vida, entretanto não se vê como limitada pelas dificuldades físicas ou emocionais que possuem. Dentre os 8 domínios do questionário SF 36, três chamam a atenção para o baixo desempenho: vitalidade, aspectos sociais e saúde mental. 
No domínio vitalidade, mais da metade $(52,5 \%)$ dos docentes obtiveram a percepção de "total falta" de vitalidade, seguidos de $37,5 \%$ de indicador de vitalidade "ruim". Isto representa uma qualidade de vida muito baixa neste domínio, o que tem sido observado em outro estudo, como o de Silveira et al. (2011), que utilizou o mesmo instrumento avaliando docentes do ensino fundamental, no qual as autoras encontraram baixos índices de vitalidade e saúde mental nos professores.

Já o domínio aspectos sociais representa a qualidade das interações sociais dos indivíduos e obteve como totalidade de respostas classificadas como qualidade ruim ou muito ruim. Considerando que o professor é tido como um sujeito social, cuja profissão é pautada pelas relações interpessoais (ANDRADE; CARDOSO, 2015), fatores relacionados ao convívio social de trabalho e lazer possuem grande relevância para estes profissionais. Moreno et al. (2016) consideram como um dos fatores comprometedores à qualidade de vida dos professores o fato destes utilizarem frequentemente seus horários de lazer e convívio social para atividades do trabalho. Na pesquisa por eles realizada, $75 \%$ dos participantes referiram trabalhar regularmente aos finais de semana, restando-lhes como tempo de atividade de lazer aproximadamente de 5 a 10 horas por semana. Dalagasperina e Monteiro (2016) alegam que a desproporcionalidade entre as exigências das atividades docentes e a carga horária semanal são queixas comuns e contribuem para o desenvolvimento do estresse docente. Dados semelhantes foram encontrados por Vale et al. (2015); Abreu et al. (2016); Souza et al. (2017) e Silveira et al. (2011).

No que diz respeito à saúde mental dos docentes, os estudos são numerosos e variados, envolvendo docentes de diferentes níveis de ensino (fundamental, médio e superior), tanto da rede pública quanto privada. Todos parecem ser consensuais ao apresentar altos índices de comprometimento da saúde mental de professores (LEITE; NOGUEIRA, 2017; SOUZA et al., 2017; DALAGASPERINA; MONTEIRO 2016; SANTOS et al., 2016). Na presente pesquisa, os resultados não foram diferentes: $65 \%$ dos docentes avaliaram sua qualidade de saúde mental como ruim (22,5\%) ou muito ruim (42,5\%), conforme destacado na Tabela 3.

Leite e Nogueira (2017) relatam que as cargas psíquicas envolvidas na atividade docente são intensas e enumeram fatores como preditores de prazer na atividade docente: a identidade de ser professor, produção de conhecimento, impacto social da função docente, a ampla interação pessoal e a construção de laços afetivos. Já os preditores de sofrimento psíquico estão relacionados com os conflitos interpessoais, a exaustão física e mental, a precarização das condições de trabalho e o aumento constante da carga laboral.

Souza et al. (2017), em seu estudo sobre publicações das condições de saúde de docentes de universidades públicas, relatam que a precarização das condições de trabalho afeta a saúde destes profissionais, em especial a saúde mental. Além do pouco tempo de lazer disponibilizado, os autores salientam o mérito docente vinculado a resultados de produtividade (publicações científicas), a competitividade entre os pares e o grande envolvimento dos docentes em atividades que não são vistas como parte do trabalho acadêmico (relatórios, participações em comissões, encargos administrativos) como comprometedores da saúde mental docente.

Dalagasperina e Monteiro (2016) incluem a esta lista a execução de diversos papéis sociais, a infinidade de tarefas, a dificuldade em cumprir prazos, a preocupação com os alunos e a falta de autonomia. Santos et al. (2016) relatam que o aumento na quantidade de alunos por turma, assim como na quantidade de turmas em que o docente ministra aulas, também contribuem para este desgaste.

Além destes fatores, Moreno (2016) e Cortez et al. (2017) chamam a atenção para a necessidade da dupla jornada, comum à muitos docentes, em especial no ensino superior. Pimenta e Anastasiou (2002) citam que o docente do ensino superior é alguém que "torna-se professor da noite para o dia", visto que em boa parte dos casos são profissionais de 
determinadas áreas que optam pela docência, mas que muitas vezes não deixam sua atividade profissional não docente. Assim, além de não serem adequadamente preparados para os desafios da docência, precisam adequar suas rotinas para cumprir com a dupla jornada e diferentes demandas.

Ao realizar a inferência estatística sobre as variáveis, verificou-se que existe correlação estatisticamente significativa entre Vitalidade e Percepção da prática docente ter influência na saúde do profissional $\left(X^{2}=23,35 ; p<0,01\right)$. Neste sentido, uma vitalidade avaliada como muito ruim associa-se às pessoas que percebem que o exercício da docência afeta a sua saúde. Desta forma, percebe-se que os docentes têm a crença de que a função docente influencia na sua vitalidade.

Tabela 4- Correlação entre a percepção da influência na saúde e vitalidade

\begin{tabular}{|c|c|c|c|c|c|c|c|c|c|}
\hline & & \multicolumn{4}{|c|}{ Vitalidade } & \multicolumn{4}{|c|}{ Testes qui-quadrado } \\
\hline & & $\begin{array}{l}\text { Muito } \\
\text { Boa }\end{array}$ & Boa & Ruim & $\begin{array}{l}\text { Muito } \\
\text { ruim }\end{array}$ & Total & Valor & df & $\begin{array}{c}\text { Significâ } \\
\text { ncia }\end{array}$ \\
\hline Na sua opinião, o exercício & Sim & 4 & 1 & 30 & 41 & 76 & 23,35 & 3 & 0,000 \\
\hline $\begin{array}{l}\text { da docência influencia na } \\
\text { sua saúde }\end{array}$ & Não & 3 & 0 & 0 & 1 & 4 & & & \\
\hline Total & & 7 & 1 & 30 & 42 & 80 & & & \\
\hline
\end{tabular}

Na literatura é possível observar que a maior quantidade de referências acerca da saúde docente diz respeito à saúde psíquica, que tem grande relação com a vitalidade. Revisões bibliográficas, como a realizada por Davoglio et al. (2015), destacam um maior índice de queixas por parte dos docentes de ordem psíquica e emocional do que de ordem física. Sinais de exaustão emocional, desânimo, estresse e ansiedade são relatados por vários outros estudos (VALE et al., 2015; ABREU et al., 2016; DALAGASPERINA; MONTEIRO, 2016; MORENO, 2016; LEITE; NOGUEIRA, 2017; SOUZA et al., 2017; BARBOSA et al., 2018).

Com o intuito de pesquisar se existem diferenças significativas entre profissionais que acreditam que o exercício da docência tem um efeito direto sobre a saúde de quem a exerce e quem pensa que não, ao nível da percepção da qualidade de vida, desenvolveu-se uma análise de diferenciação com recurso ao teste estatístico $U$ de Mann-Whitney, este averigua se as ordens médias de dois grupos independentes ao nível de uma variável dependente ordinal (categorias do SF-36) diferem. A Tabela 5 apresenta os resultados destas análises.

Tabela 5 - Diferenças nas categorias do SF-36 em função da percepção acerca da influência da docência na saúde

\begin{tabular}{|c|c|c|c|c|}
\hline Categorias Teste SF-36 & $\begin{array}{c}\text { Influência da } \\
\text { docência na saúde }\end{array}$ & $\mathbf{N}$ & Média & $\begin{array}{c}\text { U de Mann- } \\
\text { Whitney }\end{array}$ \\
\hline \multirow{2}{*}{ Capacidade funcional } & Sim & 76 & 39,76 & \multirow{2}{*}{$96,000^{*}$} \\
\hline & Não & 4 & 54,5 & \\
\hline \multirow{2}{*}{ Limitação por aspectos físicos } & Sim & 76 & 40,5 & \multirow{2}{*}{152,000} \\
\hline & Não & 4 & 40,5 & \\
\hline \multirow{2}{*}{ Dor } & Sim & 76 & 40,5 & \multirow{2}{*}{152,000} \\
\hline & Não & 4 & 40,5 & \\
\hline \multirow{2}{*}{ Estado geral de saúde } & Sim & 76 & 40,5 & \multirow{2}{*}{152,000} \\
\hline & Não & 4 & 40,5 & \\
\hline \multirow{2}{*}{ Vitalidade } & Sim & 76 & 41,69 & \multirow{2}{*}{$61,500^{*}$} \\
\hline & Não & 4 & 17,88 & \\
\hline \multirow{2}{*}{ Aspectos Sociais } & Sim & 76 & 39,08 & \multirow{2}{*}{$44,000^{* *}$} \\
\hline & Não & 4 & 67,5 & \\
\hline
\end{tabular}

Perspectivas em Gestão \& Conhecimento, João Pessoa, v. 10, n. 2, p. 143-158, maio/ago. 2020. 
Michelle Cardoso Machado dos Santos; Adriana Yanina Ortiz; Solange Franci Raimundo Yaegashi; Arthur Gualberto Barcelar da Cruz Urpia; Regiane da Silva Macuch

\begin{tabular}{|c|c|c|c|c|}
\hline \multirow{2}{*}{ Limitação por aspectos emocionais } & Sim & 76 & 40,5 & \multirow{2}{*}{152,000} \\
\hline & Não & 4 & 40,5 & \\
\hline \multirow{2}{*}{ Saúde mental } & Sim & 76 & 39,86 & \multirow{2}{*}{103,500} \\
\hline & Não & & 52,63 & \\
\hline
\end{tabular}

${ }^{*} p<0,05 ;{ }^{* *} p<0,01$

Fonte: Dados de Pesquisa (2019)

Em função do observado na Tabela 9, existem diferenças estatisticamente significativas entre as pessoas que pensam que exercer a docência tem consequências para a saúde e quem não, na Capacidade Funcional $(U=96,000 ; p<0,05)$, a Vitalidade $(U=61,500 ; p<$ $0,05)$ e os Aspectos Sociais $(U=44,000 ; p<0,01)$. Em todos os casos, os resultados são favoráveis aos sujeitos que acreditam que ser docente tem algumas implicações para a saúde.

Destes itens, novamente o domínio Aspectos Sociais se destaca, ao apresentar o maior índice de significância. Isso reforça a percepção de que o docente é um ser social, que valoriza suas relações interpessoais. Entretanto, é interessante como estas relações possuem duplo sentido na vida do docente. Ao mesmo tempo que estudos mostram que o professor busca e valoriza as relações interpessoais, muitas vezes queixa-se da necessidade de isolamento para cumprir suas demandas (SANTOS et al., 2016). Assim, trabalhar com pessoas, algo que é complexo e que exige um grande esforço, é motivo de estresse psicológico e físico (BARBOSA et al., 2018).

Alguns autores (FONTANA; PINHEIRO, 2010, CORTEZ et al., 2017, SANTOS et al., 2016, BENEVIDES-PEREIRA, 2012) apresentam a baixa realização pessoal do professor como um fator preponderante no desenvolvimento de transtornos físicos (dor) e psíquicos (ansiedade, síndrome de Burnout). Ao tratar do tema estresse ocupacional, Prado (2016) enfatiza que este tipo de disfunção possui vertentes biológicas, psicológicas e sociológicas que são complementares e interligadas. Como forma de enfrentamento destas questões, este autor destaca a necessidade de desenvolvimento de estratégias com foco na emoção e no problema. Estratégias estas que podem ser norteadas pelos princípios da GC, com o favorecimento do aprendizado coletivo, da organização dos conhecimentos adquiridos, do compartilhamento de saberes e experiências por meio de cafés do conhecimento e comunidades de prática (WENGER, 1998).

Leite e Nogueira (2017) afirmam que "refletir sobre a situação e os processos de saúde implica em analisar modelos de gestão", o que é perfeitamente condizente com a vertente defendida nesta pesquisa. Assim, em resposta à pergunta da pesquisa envolvendo a percepção de um grupo de docente sobre suas condições de saúde, observou-se que $92,5 \%$ deles acreditam que a saúde influencia a gestão do trabalho pedagógico.

Estes docentes possuem uma boa avaliação da própria saúde, sendo os aspectos psicológicos e emocionais os mais comprometidos, o que vai ao encontro de outras publicações de pesquisas realizadas com o mesmo tipo de população. A condição de saúde destes professores influencia principalmente na produção científica e na inovação das metodologias de ensino, o que é preocupante, visto que são duas funções essenciais no percurso da carreira. Ser professor está relacionado com a paixão pelo conhecimento e pela disseminação deste e além das necessidades quantitativas de produção e boas avaliações das IES às quais pertencem, a realização pessoal do professor está vinculada à percepção do cumprimento desta missão.

\section{CONSIDERAÇÕES FINAIS}

A fim de proporcionar melhor entendimento sobre a situação atual da função docente e proporcionar meios para uma intervenção de melhorias com base em ferramentas da GC,

Perspectivas em Gestão \& Conhecimento, João Pessoa, v. 10, n. 2, p. 143-158, maio/ago. 2020. 
este estudo buscou analisar a relação entre a função docente e a percepção da influência desta atividade sobre a saúde e qualidade de vida destes profissionais. Diante das análises realizadas, conclui-se que a atividade docente exige dedicação física, mental e emocional, sendo que a condição de saúde percebida pelo docente influencia no desempenho das suas atividades como docente.

Neste estudo, com 80 docentes de uma IES privada, foram obtidas informações acerca da percepção do adoecimento docente e de como esta condição afeta os processos de gestão no ensino superior. Apesar do número reduzido da amostra, foi possível perceber que os dados encontrados indicam semelhanças com a literatura relacionada ao assunto, tornando possível a realização da análise sob a tríade condições de saúde-gestão do trabalho pedagógico-gestão do conhecimento, indicando que ferramentas de gestão do conhecimento podem contribuir para a melhoria das condições de saúde destes profissionais.

A carga de trabalho, as perspectivas de crescimento na carreira, as políticas organizacionais, a relação com os gestores e o adequado feedback sobre o desempenho profissional aparecem como fatores importantes da gestão que influenciam na saúde destes professores. Itens estes que estão diretamente relacionados com os modelos de gestão adotados pela instituição ou pelo modelo de gestão do trabalho pedagógico adotado na própria prática docente.

É fato que, seja de ordem pública ou privada, as IES constituem organizações com missões e culturas definidas e que precisam adequar-se ao mundo atual para manterem-se "vivas" e aprendentes. O docente foi, é e continuará sendo um dos protagonistas destas organizações e necessita ter apoio para desempenhar suas funções adequadamente, correspondendo às suas próprias expectativas, além das necessidades institucionais e sociais.

Os princípios do desenvolvimento de um capital psicológico positivo têm sido tratados de forma crescente na literatura. Muitos dos estudos citados neste trabalho destacam como a identificação com o grupo e com a missão da instituição, o suporte organizacional, o feedback das atividades desempenhadas, cuidados com a ergonomia e a participação nos processos de gestão e decisão influenciam positivamente na saúde e na produtividade docente. Desse modo, a importância do desenvolvimento do capital psicológico no controle dos danos decorrentes do trabalho e o aprimoramento de aspectos da personalidade como eficácia, esperança, otimismo e resiliência contribuem para a saúde psíquica e emocional de docentes no controle da ansiedade e das situações de estresse.

Em forma de conclusão, considera-se que buscar estratégias e ferramentas de gestão do conhecimento que valorizem as pessoas e o capital intelectual presente nelas constitui um plantio de boas sementes, capaz de agregar maior valor às instituições de ensino e desenvolvimento de competitividade e sustentabilidade. Para muito além disto, desenvolver práticas e processos de gestão para a capacitação e cuidado com os docentes constituem formas de aprimoramento da própria humanidade.

\section{REFERÊNCIAS}

ABREU, M. A. G. M; COELHO, M. T. A. D.; RIBEIRO, J. L. L. S. Percepção de professores universitários sobre as repercussões do seu trabalho na própria saúde. RBPG, Brasília, v.13, n. 31, p. 465 - 486, maio/ago. 2016.

AGUIAR, M.C.C.; Um olhar sobre desafios da gestão didático-pedagógica no Ensino Superior. Revista Pro Posições, v. 27, n. 3, set/dez. 2016 
ALTBCH, P. Os papéis complexos das universidades no período de globalização. In: MULLER,V. (trad) Educação superior em um tempo de transformação: novas dinâmicas para a responsabilidade social. Porto Alegre: EDIPUCRS, 2009.

ANDRADE, P. S; CARDOSO, T. A. O. Prazer e dor na docência: revisão bibliográfica sobre a Síndrome de Burnout. Saúde Soc., São Paulo, v. 21, n. 1, p. 129-140, 2012.

BARBOSA, A. L. K. H.; GROSSI-MILANI, R.; SILVA, E. S.; MACUCH, R. S.; CORTEZ, L. E. R. Síndrome de burnout em docentes universitários de instituições privadas. Revista interdisciplinar de estudos em saúde, v. 7, p. 70-80, 2018.

BENEVIDES-PEREIRA, A. M. T. Considerações sobre a síndrome de burnout e seu impacto no ensino. Bol Psicol., 62(137):155-68, 2012.

BERNARDO, M.H.; Produtivismo e precariedade subjetiva na universidade pública: o desgaste mental dos docentes. Psicologia \& Sociedade, v. 26, n. spe, p. 129-139, 2014.

BOLFER, M. M. O; Reflexões sobre a prática docente: estudo de caso sobre a formação continuada de professores universitários. 2008. 238f. Tese (Doutorado em Educação) UNIMEP, Piracicaba, SP, 2008.

BORGES, E. F.; CECÍLIO, S. O trabalho docente no Brasil [década de 1950 aos dias atuais]: a precarização no contexto de (re)democratização. HOLOS, [S.I.], v. 5, p. 177-194, nov. 2018. Disponível em: http://www2.ifrn.edu.br/ojs/index.php/HOLOS/article/view/6535. Acesso em: 16 de fevereiro de 2019. doi:https://doi.org/10.15628/holos.2018.6535.

CAMPOS, G. M.; CUNHA, D. M.; Perfil do absenteísmo docente na rede municipal de educação de Belo Horizonte/MG no período de 2011 a 2014. Revista Pedagógica, v.19, n. 40, jan./abr. 2017.

CHERMAN, A.; ROCHA-PINTO, S. R.; Valoração do conhecimento nas organizações e sua incorporação nas práticas e rotinas organizacionais. Revista Brasileira de Gestão de Negócios, São Paulo, v. 18, n. 61, p. 416-435 jul./set. 2016

CICONELLI, R. M.; FERRAZ, M. B.; SANTOS, W.; MEIÑAO, I.; QUARESMA, M. R. Tradução para a língua portuguesa e validação do questionário genérico de avaliação de qualidade de vida SF36 (Brasil SF-36). Revista Brasileira de Reumatologia, v. 39, n. 3, p. 143-150, 1999.

COLLIE, R. J.; SHAPKA, J. D.; PERRY, N. E. School Climate and Social-Emotional Learning: Predicting Teacher Stress, Job Satisfaction, and Teaching Efficacy. Journal of Educational Psychology, v. 104, n. 4, p. 1189-1204, 2012.

CORTEZ, P. A. et al. A saúde docente no trabalho: apontamentos a partir da literatura recente. Caderno de Saúde Coletiva, Rio de Janeiro, v. 25, n. 1, p. 113-122, 2017.

DALAGASPERINA, P.; MONTEIRO, J. K. Estresse e docência: um estudo no ensino superior privado. Rev. Subjetividades. Fortaleza, v. 16, n. 1, p. 36-51, abr. 2016. Disponível em http://pepsic.bvsalud.org/scielo.php?script=sci arttext\&pid=S235907692016000100004\&Ing= pt\&nrm=iso. Acesso em: 04 fev. 2019. 
DALKIR, K. Knowledge management in theory and practice. 2. ed. Massachusetts: Institute of Technology, 2013.

DAVOGLIO, T. R., LETTNIN, C. da C., BALDISSERA, C. G. (2015). Avaliação da qualidade de vida em docentes brasileiros: uma revisão sistemática. Pro-Posições, v. 26, n. 3, p. 145-166, 2015. Disponível: http://periodicos.sbu.unicamp.br/ojs/index.php/proposic/article/view/8642376. Acesso em: 01 jun. 2019

DELORS, J. Educação: um tesouro a descobrir. 2ed. São Paulo: Cortez Elabore três tipos de fichas (citação, resumo e analítica) com base no texto: "Os 4 pilares da Educação" de Jacques Delors. Brasília, DF: MEC/UNESCO, 2003.

FONTANA, R.T.; PINHEIRO, D.A. Condições de saúde auto-referidas de professores de uma universidade regional. Rev Gaúcha Enferm, Porto Alegre, v. 31, n. 2, p. 270-276, jun. 2010.

HUBERMAN, M. O ciclo de vida profissional dos professores. In: NÓVOA, A. (org.). Vidas de professores. 2. ed. Porto: Porto, 2000. p. 31-61.

ILO. International Labour Office. Stress prevention at work checkpoints. Genebra, ILO. 2012.

LE BOTERF, G. Construir as competências individuais e colectivas. Tradução: Maria Dolores Garrido. Edições ASA, Porto, Portugal, 2005.

LEITE, A.F.; NOGUEIRA, J.A.D.; Fatores condicionantes de saúde relacionados ao trabalho de professores universitários da área da saúde: uma revisão integrativa. Revista Brasileira de Saúde Ocupacional, v. 47, n. 6, 2017.

LIU, C; WANG, S.; SHEN, X.; LI M.; WANG, L. The association between organizational behavior factors and health-related quality $f$ life among college teachers: a cross- sectional study. Health an quality life outcomes. 2015.

MARTINS, H. F.; FERREIRA, A. C. Capital Intelectual e Ensino Superior: análise e perspectivas. Perspectivas em Gestão \& Conhecimento, João Pessoa, v. 5, n. 2, p. 83-110, jul./dez. 2015. Disponível em: http://periodicos.ufpb.br/ojs2/index.php/pgc. Acesso em: 16 de junho de 2017.

MORENO, L. A.; DIAS, M. A. F.; SARDA JUNIOR, J.; DIAS, I. D. Prevalência de doenças ocupacionais em professores de uma Instituição de ensino superior do Vale do Itajaí-SC. Revista Brasileira de Tecnologias Sociais, v.3, n. 1, 2016.

NONAKA, I.; TAKEUCHI, H. The knowledge creating company: how japanese companies create the dynamics of innovation. New York: Oxford University Press, 1993.

PERRENOUD, P. Dez novas competências para ensinar. Porto Alegre: Artmed Editora, 2000.

PIMENTA, S. G.; ANASTASIOU, L. G. C. Docência no ensino superior. São Paulo. Cortez Editora, 2002. 
POSPICHIL, B. et al. Capital Intelectual Individual e Coletivo: estudo em uma industria química. Revista de Ciências da Administração, Florianópolis, p. 8-25, ago. 2018. Disponível em: https://periodicos.ufsc.br/index.php/adm/article/view/50119. Acesso em: 01 jun. 2019.

DO PRADO, C. E. P. Estresse ocupacional: causas e consequências. Revista Brasileira Medicina do Trabalho, v. 14, n. 3, p. 285-9, 2016.

SANTOS, C. C.; PEREIRA, F.; LOPES, A. Efeitos da intensificação do trabalho no ensino superior: da fragmentação à articulação entre investigação, ensino, gestão académica e transferência de conhecimento Rev. Portuguesa de Educação, v. 29, n. 1, p. 295-321, 2016.

SILVEIRA, R. E.; REIS, N. A.; SANTOS, A. S.; BORGES, M. R. Qualidade de vida de docentes do ensino fundamental de um município brasileiro. Revista de Enfermagem Referência, III Série, n. 4. p.115-123, 2011.

SOUZA, K. R. et al. A nova organização do trabalho na universidade pública: consequências coletivas da precarização na saúde dos docentes. Ciência \& Saúde Coletiva, v. 22, n. 11, p. 3667-3676, 2017.

VALE, S. F.; MACIEL, R. H.; CARLOTTO, M. S. Propriedades psicométricas da escala de percepção de estressores ocupacionais dos professores (EPEOP). Psicologia Escolar e Educacional, v. 19, n. 3, p. 575- 583, septiembre/diciembre, 2015.

WENGER, E. Communities of practice: learning, meaning and identity. Cambridge, UK: Cambridge University, 1998.

World Health Organization, ICD-11- International Classification of Diseases, $11^{\text {th }}$ Revision, WHO; 2019. Disponível em: https://icd.who.int/en, acesso em 01 jun. 2019.

YAEGASHI, S. F. R.; BENEVIDES-PEREIRA, A. M. T; ALVES, I. C. B. Docência e burnout: Um estudo com professores do ensino fundamental. In: YAEGASHI, S. F. R.; BENEVIDES-PEREIRA, A. M. T. Psicologia e Educação: Conexão entre saberes. São Paulo: Casa do Psicólogo, 2013. 